\title{
University Students Seeking Hormonal Emergency Contraception: Why Do They not Want Pregnancy Now? When is it Suitable to Have Children?
}

\author{
AIRA VIRTALA, M.D., Chief Physician ${ }^{1}$ \\ IRMA VIRJO, M.D. Ph.D., Professor of General Practice ${ }^{2}$ \\ ${ }^{1}$ Finnish Student Health Service, Tampere, Finland \\ ${ }^{2}$ Medical School, Department of General Practice, \\ University of Tampere, Finland
}

\begin{abstract}
University students who sought hormonal emergency contraception (EC) in the Tampere Student Health Station during the period 1.9.2000-31.12.2001 received a questionnaire on their use of it. Of the total, 114 responded (67\%). The aim of this study was to ascertain why the respondents did not want to get pregnant now and when it would be suitable for them to get children. Free answers to these questions were analysed using a collective consensus method. The main reasons for not wanting pregnancy now were unfinished studies and the non-steady character of the relationship. Almost all planned to become pregnant some day in the future when their life situation was appropriate, usually at the age of about 30 years.
\end{abstract}

Key words: family planning, contraceptive behaviour, hormonal emergency contraception, postponing pregnancy, university students, Finland

\section{Introduction}

According to the Finnish Student Health Survey eight percent of female students aged 19-34 years had children (Kunttu and Huttunen 2001). The respective proportion for the Finnish population at large was 38\% in the year 2000 (Statistics Finland, Population Statistics). Students seem to postpone pregnancy. Family planning is thus for students in their life situation a matter of immediate concern.

The Finnish Student Heath Service (FSHS) provides for all university students in Finland. The organisation has health stations in 16 cities. It is financed by the Social Insurance Institution, the students and student unions, the university cities and the State of Finland. Students pay a yearly obligatory health care fee of 31.62 EUR as a 
part of the Student Unions membership fee, whereafter they can visit e.g. a general practitioner or a public health nurse without charge.

The most common single reason for consultation in The FSHS is contraception. E.g. in the Tampere station in 2000 these consultations comprised some $13 \%$ of all physician consultations. According to one Health Survey $51 \%$ of female Finnish students used oral contraceptives in 2000 (Kunttu and Huttunen 2001). This notwithstanding, hormonal emergency contraception (EC) is also used. In Finland hormonal EC came onto the market in 1986. To use EC a woman needed a prescription from a physician until May 2002, since then a woman 15 years or older can obtain EC from a pharmacy without prescription.

Finnish University students' use of hormonal emergency contraception was studied at the Finnish Student Health Service in Tampere 2000-2001 (Virjo and Virtala 2003). EC was sought from the FSHS 222 times during 16 months among a total of 10,133 female students. This means that $1.6 \%$ of all female students sought emergency contraception during one year. This is of course a minimum estimate. Students can use other health services available in the community, but most probably do so on a very low scale, since they have easy and cheap access to the FSHS. They are also well aware of the time within which the EC pills need to be taken.

Two thirds of respondents reported having used contraception during the intercourse after which they sought emergency contraception. Condom failure was the most usual reason for the need of EC. One third of respondents had not used any contraception. In open answers respondents gave many explanations as to why they had used no contraception, e.g. having been over-passionate or drunk (Virjo and Virtala 2003).

EC has been studied from many points of view, as Ellertson and associates (2000) have shown in their extensive review article. There are studies on the extent of use and on the service delivery. Women's knowledge of EC and the available information sources have also been studied. There are also studies concerning attitudes and fears of side-effects. Providers' knowledge and attitudes have also been mapped out. We are not aware of studies concerned with EC users' plans concerning pregnancy and child rearing.

After an unprotected intercourse women are in a situation where they have to decide whether they want to have a baby now or later. In EC women have at their disposal a safe and effective means of preventing pregnancy if they so wish (Task Force on Postovulatory Methods of Fertility Regulation 1998). The aim of this study was to analyse the reasons for postponing pregnancy given by EC seekers at Finnish Student Health Service in Tampere 2000-2001. 


\section{Material and methods}

All students who sought EC at Finnish Student Health Service's health stations in Tampere, received at the end of the visit an envelope containing a covering letter, a questionnaire and a prepaid response envelope. The response letter was addressed to one of the authors at the University. Both physicians and public health nurses were expected to give this envelope to all $\mathrm{EC}$ seekers who consulted during the period from 1.9. 2000 to 31.12. 2001. As these subjects were not registered, we could not send any reminders. They answered the questionnaires anonymously. All questionnaires returned by the end of January 2002 were taken for analysis.

Two hundred envelopes were prepared for the study. Of these the physicians and public health nurses delivered 169. By the end of January 2002114 had been returned, giving a response rate of $67 \%$. From the files of the Finnish Student Health Service health stations in Tampere 217 persons were found to have made altogether 252 visits for EC during the study period. Some visited both a nurse and a doctor. Five women used EC twice during the study period. Thus 48 persons did not receive the envelope, including a few students who declined to accept it. In most cases the personnel probably forgot to give the envelope.

The questionnaires contained questions concerning the intercourse that had led to the need for EC, contraception information sources and future plans concerning contraception and pregnancies. Both structured and open questions were included.

There were three questions concerning reproductive plans. Respondents were asked whether they planned to have children / more children in the future. The response alternatives were: yes/no/I cannot say. Two open questions: "What is your main reason for not wishing to get pregnant now?" and "What do you think is the best time to have children?" The respondents answered freely to these questions, some in a few words, some with a fuller explanation comprising many sentences. All answers were written as such into the computer, and they formed a large qualitative material. This was analysed using "a collective consensus method" originally developed for the analysis of students' written accounts of problem-based learning tutorial sessions (Virtanen et al. 1999).

The analysis comprised the following stages:

1. Preliminary reading and categorisation. Both authors read the material several times individually to get an impression of the most common or most interesting features of the answers. The task was to find typical categories of answers.

2. Consensus discussion of categories. The authors discussed together the categories proposed and agreed on the categories for future analysis. 
3. Analysis of the texts. The authors read the answers individually again to find direct excerpts referring to the categories agreed on at stage 2.

4. Consensus discussion of the citations. The authors discussed all citations found and agreed to which category they belonged.

5. Description of the categories. The authors worked first individually to find citations to describe each category. Finally these citations were decided in a joint discussion.

Some answers were very short and clearly belonged to only one category. Some free answers were so long and richly explicative that they produced material for several categories.

\section{Respondents}

The age of the respondents varied between 19-34 years, $76 \%$ of respondents being 20-26 years old. The study year varied from the first to the tenth. Marital status: $81 \%$ of respondents were single, $16 \%$ were cohabiting, three $(2.6 \%)$ were married and one $(0.9 \%)$ was divorced. Five of the respondents had children. Three respondents mentioned having experienced one induced abortion.

The partner in the intercourse leading to the need for $\mathrm{EC}$ had been a permanent one in $65 \%$ of cases: boyfriend in $49 \%$, live-in boyfriend in $13 \%$ and husband in $3 \%$. Of the remainder $16 \%$ knew the partner previously, but $14 \%$ stated that the partner was a previously unknown person. In the remaining cases the partner was variously described as e.g. a former boyfriend.

\section{Results}

The distribution of answers to the question: "Do you plan to have children?" was: $78 \%$ answered yes, $4 \%$ no and the rest (18\%) could not say. These three respondent groups were compared. There was no statistically significant difference concerning marital status or partner in the intercourse leading to seeking EC. Nor did the groups differ in respect of use of contraception in that intercourse. The mean age of all respondents was 23.5 years. The mean age of those who planned to have children some time in the future was 23.3 years. The corresponding ages for those who did not plan to have children or who could not say were 24.8 years and 24.0 years. The differences were not statistically significant. 
The analysis of open answers to the question "What is your main reason for not wishing to get pregnant now?" yielded eight categories (Table 1).

Table 1. "What is your main reason for not wanting to get pregnant now?" Categorisation of EC seekers' answers ( $\mathrm{n}=112$ out of a total of 114 respondents) at the Finnish Student Health Service stations in Tampere, Finland in 2000-2001, and the number of citations in each category.

\begin{tabular}{lc}
\hline Category & Number of citations \\
\hline "I wish to complete my studies first" & 56 \\
"I do not have a steady relationship with my partner" & 47 \\
"Immature to be a mother" & 28 \\
"I want to enjoy my youth" & 22 \\
"A miserable economic situation" & 14 \\
"I am too young" & 13 \\
"I don't want to become a single mother at this age" & 6 \\
Miscellaneous reasons: "My life situation is not suitable for that" & 23 \\
\hline
\end{tabular}

Category 1 "I wish to complete my studies first"

The majority of answers represented this standpoint. It was expressed in many different ways. "The studies must be finished". Some were just at the beginning of studies. "I have just started my studies in the field of my choice. I would not want to interrupt my studies immediately". Some had plans for student exchange in the near future. "I will soon be leaving on a student exchange". Even if the studies were near completion, the respondents did not think that they could get pregnant. "The studies are near the end".

Category 2 "I do not have a steady relationship with my partner"

This category was conspicuous, the second largest. All citations here referred to the uncertain quality of the relationship. Most expressed the fact that the relationship was impermanent. The relationship could be temporary, "the partner was a previously unknown person" or "one night's affair". Some students regarded their relationship as too short, "we have known each other only two-three months and I don't know him well enough". There were also a few citations, which evinced considerable demands regarding a relationship. Even if the relationship was steady or had lasted a long time, it was not secure enough to have a child. 
"Even if I answered that my partner is a permanent boyfriend, I am not so sure of my own feelings that I would like to bind myself definitively. That is the main reason". "We have been going together only less than one year". "I don't know if I want to have a child with my present boyfriend. I would like to be married, then one can get pregnant".

Category 3 "Immature to be a mother."

The citations in this category expressed the feeling "not ready to be a mother". The important message in this category was also that the students were afraid of taking responsibility for a child "Such a responsibility is not my business at this moment. I am not ready yet, really". The students noted that they did not possess the qualities a mother should have. In addition "I would like to be more wise and more balanced" or "I could not take care of a child, I would not be a good mother at this stage in my life" or "I have never regarded myself as a mother-type, that is to say, motherhood will not succeed, I feel it is too demanding and too responsible".

There were also those who questioned the idea of getting a child at all. "I am not sure if I want children at all" or more directly "I don't want children".

Category 4 "I want to enjoy my youth. "

In this category self-interest and self-indulgence were predominant. Some of the citations could also be seen in the further somewhat larger "immature category", but here the students referred more directly to their own interest and their wish to live their own life without taking care of others. Somehow they were more positive concerning themselves. "I want to take an interest in different nice things like travel". "A lot left to see and experience!".

Life was so full of the respondent's own activities that "There is no place for a child at this moment in my life, there are hobbies, and, simply, I don't want a child now". "We are both busy".

The citations in this category included the fear that life will somehow end if they get pregnant. "My own life is still not ready." "There is no single reason why I would want to get pregnant now, there is no place for a baby in my life now".

Some respondents thought that to get a child would harm the relationship with a partner. "Both of us think that it will not pay off to "risk" our relationship by having a child". A child would also take time, which is time away from the relationship "I would like to be married because of a man, not for the sake of a child. I would like to have time to live together with a man before potential child/children". 
Category 5."A miserable economic situation".

This category, which included citations with a direct reference to money or poor economic situation, was not very large. There were citations like "No money and so on" or "Economic situation really bad" or "I would not be able to afford to feed a child". Only a few mentioned studenthood in connection with the lack of money. "The students'economic situation is not good enough". "The reason is money. Two students are not able to support life for a child, at least not as well as one would hope".

Category 6. "I am too young".

Citations in this category refer to young age as an obstacle to being a mother. "I am a child myself". "I am not an adult". "I am not old enough to take responsibility".

Category 7. "I don't want to become a single mother at this age".

The unfavorable status of a single mother was mentioned in some citations. "It is not tempting to be a single mother." or "Life is hard for a single mother."

Category 8. Miscellaneous reasons. "My life situation is not suitable."

In this category we gathered citations where different separate factors were expressed as preventing getting pregnant now. Some already had small children at home. "There are two babies with diapers at home." Some students were seriously ill, they had depression or cancer. Disease and death of relatives were also mentioned. There were miscellaneous remarks on attitude-related matters in some citations. "My partner does not want to have children" or "I don't want children with this person" or "I don't like children". "Children originate in love-making, there were no emotions in this case, only physical performance".

Table 2. "What do you think is the best time to get children?" Categorisation of EC seekers' answers ( $\mathrm{n}=111$ out of a total of 114 respondents) at the Finnish Student Health Service stations in Tampere, Finland in 2000-2001, and the number of citations in each category.

\begin{tabular}{lc}
\hline Category & Number of citations \\
\hline "At about 30 years of age" & 63 \\
"When I have graduated" & 57 \\
"When one is living in a safe, permanent relationship" & 39 \\
"When I have got a permanent job" & 31 \\
"When one wants to have them" & 20 \\
"When the economic situation is well established" & 11 \\
\hline
\end{tabular}


The analysis of open answers to the question "What do you think is the best time to get children?" yielded six categories (Table 2).

Category 1 "About 30 years of age".

In this category 46 students estimated the best age by mentioning a certain age, and 17 answered after how many years they assessed they would be ready to get pregnant. The age was then calculated from their actual age.

In about half of the citations here the best age was estimated to be around 30 years. Fifteen respondents assessed the best age to be under 30 years; only two of them specified 20-25 years. Fourteen thought the best age to be over 30 years, two of them over 35 years. Obviously even if the respondent was older, the best time was in the future.

\section{Category 2 "When I have graduated".}

This category was almost as large as the first. Respondents here thought that the correct time for children was when studies were over or at least almost finished. This was expressed in many different ways. "When we have graduated from university". "Some later time, after graduation". "Studies over". "When one has got a degree". "When studies are near the end would be an ideal time".

Category 3. "When one is living in a safe, permanent relationship".

A permanent relationship was for many respondents a self-evident condition before one could consider having a child. There were citations like "The requirement is a stable relationship, of course" and "The most important criterion is a permanent relationship. When/if such exists at some time, I can think of getting children". Some respondents felt it important that "both want to have a child". Many citations expressed the view that both parties should take responsibility for a child "I want to be sure that the father of a child participates in taking care and bringing up the child. That means he would be a husband or otherwise a steady partner". Many respondents regarded a permanent relationship as more important than studies. "Most important is that the relationship with the father of the child feels good, sure and permanent, then it does not matter if some studies are left".

Category 4 "When one has got a permanent job."

This category included references to "a job" or a "permanent job". Some felt that the time for children comes "when a career is in good start" or "After working for some years would be ideal". Furthermore "Both have worked for some time in the field of their choice". 
Category 5. "When one wants to have them".

These citations referred to the wish and feelings to have a child. "When both parents of a child feel ready for parenthood and binding with each other". "When one is ready for responsibility". Only one respondent questioned the prevailing assumption that it is possible to plan everything in life. "It is not possible to make so detailed plans. Maybe, when one is familiar enough with oneself and the partner. By this I mean that you need not seek a divorce for the most strange reasons." There was only one reference to happiness. "The best time is when one is happily married". For some respondents there was no good time for children at all. "It depends on a person. Never for me as I see it now" or "I don't want children".

Category 6. "When the economic situation is well established".

This smallest category contained citations with direct reference to the economic situation. "Steady income". "When one is able to take care of children economically". When respondents mentioned income or a secure money situation, it was not the only criterion for the good time to get children. Together with references to the economic situation they most often also stated other important things. "When I have finished my studies, got a job, am married and we have bought/ built the house of our own". Some of them expressed the notion that "everything" should be perfect. "When there is a man, a house and a job and an otherwise secure life".

\section{Discussion}

The data for this study were gathered during a fairly long period. The physicians and nurses involved were engaged in their usual daily work, and it is not surprising that they sometimes forgot to give the questionnaire to an EC client. The response rate was $67 \%$, but the respondents constituted $53 \%$ of all EC seekers during the study period. To what extent do they represent the whole group? Their age distribution did not differ from that of all EC clients. The results concerning use and non-use of contraception in the intercourse, which led to the need for EC, have been presented to the staff of the FSHS health station in Tampere and discussed together. The staff were of the opinion that they very well recognised the situation the results describe, and that nothing essential was missing.

Future plans for getting children are usually not discussed when the consultation concerns the need for EC. We assume that these results describe well the thoughts of students who had to make the decision to use EC because they faced a real possibility of pregnancy. The collective consensus method is well suited for analysing this qualitative material. The categories and number of answers in each of them give a 
compact summary of the answer spectrum. The categories are however not precise like quantitative data, and many answers contained material which belonged to several categories. Thus the categories are not appropriate for use as variables in further analysis.

In the present study the majority of respondents (78\%) wanted to have children at some better time. In the Finnish Family Barometer 2002 respondents representing the population were asked whether they planned to have children in the future (Paajanen 2002). Among women aged $18-30$ years and having no children $67 \%$ answered yes, $4 \%$ answered no, and $29 \%$ did not know. The proportion of those who planned to have children was clearly smaller than in the present study.

Five of the respondents here had children (4.4\%). This is less than the general average for students in Finland. In the Student Health Survey 2000, where Finnish undergraduate students aged 19-35 years comprised the target group, eight percent had children (Kunttu and Huttunen 2001).

In the present study the most frequently mentioned reason for not wanting pregnancy now was "unfinished studies". "When I have graduated" was the second prominent expression to describe the suitable time to get children. Similar results were obtained in the Finnish Family Barometer 2002, where three out of five respondents under 30 years gave the same reason for postponing pregnancy (Paajanen 2002).

The casual nature of the relationship was easy to understand as a reason why students did not want to get pregnant. Some seemed to set very high demands for a partnership. We may ask, how long a relationship is long enough if a period of almost one year is too short. The students were very responsible and took studies and partnership and motherhood seriously. They placed very high demands on themselves. From some citations we may conclude that students underestimated their capability to be a mother. In any case they expressed uncertainty and were afraid of responsibility. Many citations included a very idealistic picture of a mother and they felt they could not fulfil the standard they had set for themselves.

The citations where selfishness and self-indulgence could be seen as the reason for postponing childbearing were not very numerous in this study. It was also somehow encouraging to read citations where one could appreciate the eagerness to live a young person's happy and free life. These respondents accepted themselves as they were. At the same time having a child struck them as something, which takes away the joy of life. This is natural and easy to understand at a very young age, but these students were no longer all so young. 
Financial circumstances were seldom directly mentioned as a main reason for not getting pregnant. This differed from the findings in the Finnish Family Barometer 2002, where almost half of respondents answered that the uncertainty of the economic situation was the reason to postpone pregnancy (Paajanen 2002). Of course we can take it for granted that being a student implies a poorer economical status and many other citations e.g. referring to single motherhood were indirectly expressions of an uncertain economic situation.

Majority of respondents in the present study reckoned the best time for themselves to get children to be around 30 years age. In the Finnish Family Barometer the ideal age for a woman to have her first child was enquired on a general level. The mean ideal age was 25.5 years according to the opinion of women aged 24-29 years (Paajanen 2002). In Finland the mean age of women at the first birth was 27.7 years in the year 2002 (Stakes). The age of the respondents in the present study will probably be higher at their first delivery.

Almost as often as suitable age, respondents stated that the good time for parenthood is after finishing studies. In the University of Tampere the students began their studies at 21 years of age (median) and completed them at the age of 29 years in 2002 (http://www.uta.fi/tilastot). Two out of three students in the University of Tampere in 2001 were working during the study terms. Almost all of them stated that working had delayed their studies. The reason for working was economic. They have to finance their studies and life in general (Palokangas 2002). According to the present findings students seem not to want to risk their studies by getting pregnant.

A further requirement for a suitable time to get children was to live in a secure, permanent relationship. How can this be guaranteed? Starting a working career and having a permanent job is not easy in these years of short-term employment.

In the Finnish Family Barometer 2002 one important reason for postponing pregnancy among under 30-year-old people was the absence of "baby fever" (Paajanen 2002). None of the respondents in this study mentioned this word when they assessed the suitable time to get children, nor the absence of it as the reason for postponing pregnancy. Other expressions of wishes that could be interpreted as baby fever were also rare. This is somewhat astonishing and interesting. Possibly what is reflected here is the effect of the "emergency situation" in which these students found themselves. Because the majority of respondents, almost all, wanted to have children at some suitable time in the future, they had to give rational reasons for their use of postcoital contraception in this actual situation, and thus there was no place for feelings. 
Neither money nor a sound financial situation was the most important criterion when students assessed the best time to get a child. When it was mentioned it was mentioned together with other more important criteria.

Altogether the future plans of students who sought emergency contraception revealed very responsible persons, who took a serious attitude to their studies, who wanted to have a life in good control and wanted to guarantee everything before they would come pregnant. These students lived their adolescent years in the 1990s, when the economic recession was predominating. Could this have some connection with the need to be sure of everything?

Whence comes the myth that during studies one should not build a family and get children? Perhaps we may hear a paternal or maternal voice "studies must be finished". On the other hand the present Prime Minister Matti Vanhanen's Government (2003) also states in its programme that study times will be shortened at universities. It is the Government's aim to ensure that all citizens can participate fully in working life, contribute to longer working careers, facilitate the coordination of family life and work, promote equality and make work more attractive. The Prime Minister has recently in various speeches expressed concern over the small number of children in Finnish families. He says that our society needs more children. University students might see these goals as contradictory, especially in that Finnish social and family policies motivate getting children after graduating, e.g. the parenthood allowance depends on income (Vikat 2000; Paajanen 2002).

This study material, while small and very selected, gives a true picture of the life of students. Emergency contraception is the point where the childbearing decision has to be made. The biological age of these students was ideal for pregnancy and the majority of them wanted to have children in the future. In their actual life situation they had many good rational reasons for postponing pregnancy. The use of emergency contraception gave them a real possibility to do so, and even for the future child the possibility to be born wanted. On the other hand, postponing pregnancy now could be one step in the direction of remaining childless, that is, against the wishes of most of the respondents in the long term. "To remain childless is seldom a conscious and unalterable decision, it is more often a result of many successive decisions not to get a child just now" (Paajanen 2002). Postponement of childbearing is one important reason for infertility problems, and it is a fact that a woman's biological fertility decreases rapidly after 30 years of age (Anttila 2002).

In addition to providing good and easily accessible contraception services, the Finnish Student Health Service sees as one of its tasks the prevention of infertility by finding and treating Chlamydia and other infections in an early phase. In consultation 
contacts with students concerning contraception it would be desirable also to discuss and give information on fertility and possible fertility problems at a later age (Anttila 2002). Education and working career are possible for a woman even at an older age, but getting a child is not. Even students should have reproduction rights and genuine chances to choose to have children at the age when it is most suitable psychologically and physiologically. This, if anything, is part of good sexual health.

\section{References}

Anttila, Leena. 2002. Lapsettomuuden ennaltaehkäisy. [The prevention of childlessness] Duodecim 118(5):527-30.

Ellertson, Charlotte, Tara Shochet, Kelly Blanchard, and James Trussell. 2000. Emergency Contraception: A Review of the Programmatic and Social Science Literature. Contraception 61:145-86.

Kunttu, Kristina and Teppo Huttunen. 2001. Student Health Survey 2000: a National Survey among Finnish University Students. Social security and health reports 45. Helsinki: The Social Security Insurance Institution, Finland, 2001:217.

Paajanen, Pirjo. 2002. Saako haikara tulla käymään? Perhebarometri 2002. Väestöliitto, Väestöntutkimuslaitos Katsauksia E 14/2002. [May a stork come for a visit? Family Barometer. Family Federation of Finland. Population Research Institute. Reviews E14/2002.]

Palokangas Miia. 2002. Tampereen yliopiston perustutkinto-opiskelijoiden asuminen ja toimeentulo 2001. Tampereen yliopiston ylioppilaskunta 2002. [The housing and living of undergraduate students at the University of Tampere in 2001. Student Union at the University of Tampere 2002.]

Stakes Tilastotiedotteet: Synnyttäjät, synnytykset ja vastasyntyneet 2002. [Statistical summary. STAKES Statistical information: Birth givers, births and newborn in 2002.]

Statistics Finland. Population Statistics 2000.

Task Force on Postovulatory Methods of Fertility Regulation. 1998. Randomised controlled trial of levonorgestrel versus the Yuzpe regimen of combined oral contraceptives for emergency contraception. Lancet 352:428-33.

The Programme of Prime Minister Matti Vanhanen's Government. Available at http://www.valtioneuvosto.fi/tiedostot/pdf/en/39357.pdf (21.5.2004).

Vikat, Andres. 2002. Fertility in Finland in the 1980s and 1990s: Analysis of Fertility Trend by Age and Parity. Yearbook of Population Research in Finland 38:159-78.

Virjo Irma, and Aira Virtala. 2003. Why do university students use hormonal emergency contraception? The European Journal of Contraception and Reproductive Health Care 8:139-144.

Virtanen, Pekka, Elise Kosunen, Doris Holmberg-Marttila, and Irma Virjo. 1999. What happens in PBL tutorial sessions? Analysis of medical students' written accounts. Medical Teacher 21:270-76. 